\title{
Pesquisa
}

\section{Presença de Microrganismos em Maletas e Celulares Transportados por Estudantes de Odontologia}

\author{
Presence of Microorganisms in Suitcases and Mobiles Carried by Students of \\ Dentistry
}

Carla Alves Vieira1; Jéssica Bonifácio de Carvalho; Dayane Franco Barros Mangueira Leite², Fabio Correia Sampaio ${ }^{3}$

${ }^{1}$ Graduanda do Curso de Odontologia da Universidade Federal da Paraíba. João PessoaPB/Brasil

${ }^{2}$ Professora Adjunto III do Departamento de Odontologia Restauradora da Universidade Federal da Paraíba. João Pessoa-PB/Brasil.

${ }_{3}$ Professor Titular do Departamento de Clínica e Odontologia Social da Universidade Federal da Paraíba. João Pessoa-PB/Brasil.

Autor e endereço para correspondência

Fábio Correia Sampaio, UFPB, Campus I, CCS, Departamento de Clínica e Odontologia Social Castelo Branco, João Pessoa-PB, CEP:58051-900

\section{Resumo}

Introdução: O uso de maletas para transporte de materiais e instrumentais é frequente no curso de Odontologia. Objetivo: avaliar a presença de microrganismos em maletas e celulares dos acadêmicos em Odontologia da Universidade Federal da Paraíba. Metodologia: A amostra foi constituída por 63 maletas de acadêmicos do terceiro ao décimo período. Para a coleta microbiológica, foi utilizado Swab esterilizado, umedecido em solução salina 0,9\%, acondicionado em tubos de ensaio com $3 \mathrm{~mL}$ de caldo BHI (Brain Heart Infusion) ou Sabouraud. A incubação e análises foram realizadas no Laboratório de Biologia Bucal. Os acadêmicos responderam a um questionário e os dados foram categorizados e analisados através do programa estatístico SPSS (Statistical Package for Social Science). Resultados: Para as maletas, foi observado crescimento bacteriano (caldo BHI) de todas as amostras da alça e do fundo externo, e em $95,2 \%$ das amostras do fundo interno. Houve crescimento de fungos (em caldo Sabouraud) de $66,7 \%$ das amostras coletadas na alça e no fundo interno, e de $63,5 \%$ de crescimento para o fundo externo. Para os celulares houve crescimento bacteriano em 98,4\% e 95,2\% das amostras da capa do celular e da tela, respectivamente. Para fungos, os resultados foram de $52,4 \%$ (capa) e $38,1 \%$ (tela). Conclusão: Microrganismos estão viáveis em diferentes partes das maletas e celulares dos estudantes de Odontologia da UFPB. Esses itens tem potencial para contaminar e disseminar microrganismos patogênicos para a clínica odontológica.

Descritores: Microbiologia. Contaminação. Exposição a Agentes Biológicos. 


\begin{abstract}
Introduction: The dental students frequently use suitcases for carrying materials and instruments. Objective: This study aimed to evaluate the presence of microorganisms in suitcases and cell phones of dental students of the Federal University of Paraíba (UFPB). Methodology: The sample consisted of 63 suitcases of dental students enrolled from the third to the tenth course period. Sterile Swabs, moistened with $0.9 \%$ saline solution, were used for samples collection. The material was placed in test tubes with $3 \mathrm{~mL} \mathrm{BHI} \mathrm{(Brain} \mathrm{Heart} \mathrm{Infusion)} \mathrm{or} \mathrm{Sabouraud} \mathrm{Broth.} \mathrm{The} \mathrm{incubation} \mathrm{and} \mathrm{analysis}$ was performed at the Oral Biology Laboratory. All participants responded a questionnaire. Data were categorized and analyzed using the Statistical Package for Social Science (SPSS). Results: All suitcases showed bacterial growth (BHI) in samples collected on the loop and external fundus whereas $95.2 \%$ of samples from the internal fund showed growth. Fungi (Sabouraud broth) were observed in $66.7 \%$ of the samples collected in the loop and internal fund. For the external fund $63.5 \%$ showed fungi growth. Regarding the cell phones, bacterial growth was observed in $98.4 \%$ and $95.2 \%$ of the samples from cell covers and the screen, respectively. Fungi growth was observed in $52.4 \%$ of the cell covers and $38.1 \%$ of the screens. Conclusion: Viable microorganisms were found in different parts of the suitcases of the dental students at UFPB. These items have the potential to contaminate and disseminate pathogenic microorganisms at the dental clinic.
\end{abstract}

Descriptors: Microbiology. Contamination. Exposure to Biological Agents.

\title{
Introdução
}

A Biossegurança é definida como medidas técnicas, administrativas e educacionais que têm por objetivo dotar os profissionais e as instituições de ferramentas que visem desenvolver atividades com um grau de segurança adequado para o profissional da saúde, para o meio ambiente e para a comunidade ${ }^{1}$. Mais que um conceito, a biossegurança é uma questão de consciência profissional ${ }^{2}$.

$\mathrm{Na}$ odontologia atual, o conhecimento e a atenção aos preceitos da biossegurança são de fundamental importância para o controle da contaminação cruzada ${ }^{3,4}$, que é um aspecto crucial na prática odontológica ${ }^{5,6}$. A transmissão de microrganismos exógenos de paciente para paciente, de paciente para profissional, ou ainda da equipe odontológica para paciente têm preocupado muitos profissionais, logo, um grande desafio para cirurgiões-dentistas, pesquisadores e microbiologistas é prevenir a infecção cruzada no consultório odontológico ${ }^{7}$.

Nas atividades da clínica odontológica, tão importante quanto o domínio técnico e científico é a conscientização dos riscos de contaminação que o tratamento odontológico origina. Pesquisas realizadas mostraram que todos os instrumentos odontológicos, desde os mais simples 
até os mais sofisticados, são responsáveis por carregar um universo de microrganismos patogênicos ${ }^{8,9}$.

Apesar da preocupação com a contaminação e com o risco de contrair doenças, ainda existem cirurgiões-dentistas que subestimam as normas de biossegurança ${ }^{10}$, e mesmo que haja empenho na utilização de medidas de controle da infecção cruzada, melhoras ainda são necessárias ${ }^{11}$.

Nos cursos de Odontologia, é comum o uso de maletas para o transporte de materiais e instrumentais para a clínica onde são realizados os atendimentos aos pacientes. Levando-se em consideração que as superfícies dessas maletas, assim como o que é transportado dentro delas, já estão contaminadas com microrganismos potencialmente patogênicos, essas funcionam como verdadeiros veículos de transmissão, disseminando contaminação para o interior da clínica e também levando contaminação para fora da mesma.

Os alunos de odontologia, futuros profissionais, desempenharão papel significativo na melhoria do controle de infecção pela classe odontológica ${ }^{12}$. Sendo assim, percebe-se negligência quanto aos cuidados com aparelho celular e com as maletas que servem para transportar instrumental e material dos acadêmicos de odontologia. Nessa perspectiva, o presente estudo teve como objetivo avaliar a presença de microrganismos em maletas e celulares dos acadêmicos em Odontologia da Universidade Federal da Paraíba.

\section{Metodologia}

O presente estudo foi submetido à Plataforma Brasil, ao Comitê de Ética em Pesquisa do Centro de Ciências da Saúde da Universidade Federal da Paraíba, sendo aprovado com Protocolo 0239/14 e CAAE 31030714.4.0000.5188.

A partir disso, foram selecionados aleatoriamente 63 alunos matriculados do terceiro ao décimo período do curso de Odontologia da Universidade Federal da Paraíba. Após serem dadas informações sobre o estudo, o estudante que aceitou participar da pesquisa assinou o Termo de Consentimento Livre e Esclarecido.

Para a coleta microbiológica das maletas (alça, fundo externo e fundo interno) e do aparelho celular, foi utilizado Swab esterilizado, umedecido em solução salina $0,9 \%$, acondicionado em tubos de ensaio com $3 \mathrm{ml}$ de caldo BHI (Brain Heart Infusion) ou Sabouraud Caldo, transportados em caixa térmica com gelo. As amostras foram submetidas ao período de incubação de 24 horas em estufa a $37^{\circ} \mathrm{C}$. Após esse período, foram inoculadas nos meios de 
cultura Ágar BHI, Ágar Manitol Salgado e Ágar Sabouraud, mantendo-se na estufa por mais 24 horas sob a mesma temperatura. $O$ crescimento de microrganismos foi analisado. $A$ análise foi realizada no Laboratório de Biologia Bucal-LABIAL/UFPB.

Além da coleta microbiológica, foi utilizado um questionário para cada acadêmico participante da pesquisa com informações sobre gênero, idade e período do curso do proprietário da maleta e do celular; material e tempo de uso da maleta; se o proprietário da maleta fazia a desinfecção na mesma, com que frequência era realizada e quais produtos eram utilizados. Os celulares foram categorizados em tela de vidro (tela "touchscreen") e celulares de teclado. Os questionários eram relacionados com as amostras coletadas por códigos.

Os dados foram categorizados e analisados de forma descritiva através do programa estatístico SPSS (Statistical Package for Social Science), versão 22.0. Foram analisadas as frequências.

\section{Resultados}

Em relação à maleta, no $\mathrm{BHI}$ caldo foi observado crescimento em todas as amostras da alça e do fundo externo e em 95,2\% das amostras do fundo interno. No Sabouraud caldo foi observado crescimento em $66,7 \%$ das amostras coletadas na alça, $63,5 \%$ de crescimento para o fundo externo e $66,7 \%$ para o fundo interno.

Em relação ao $\mathrm{BHI}$ ágar, todos os sítios da maleta apresentaram contaminação. Nas placas de ágar Sabouraud, todas as amostras coletadas tanto da alça quanto do fundo externo apresentaram contaminação. No fundo interno, 93,7\% das amostras apresentaram contaminação.

No que se refere ao ágar Manitol Salgado, todas as amostras coletadas na alça da maleta apresentaram crescimento, sendo $61,9 \%$ indicativas da presença de $\mathrm{S}$. aureus, $31,8 \%$ indicativas da presença de $S$. epidermidis e $6,3 \%$ das amostras indicativas da que presença tanto de $S$. aureus quando S. epidermidis. No fundo externo da maleta $98,4 \%$ das amostras apresentaram crescimento, sendo $61,9 \%$ indicativas da presença de $\mathrm{S}$. aureus, $31,7 \%$ indicativas da presença de $S$. epidermidis e $4,8 \%$ indicativas da presença das duas espécies bacterianas. Já no fundo interno da maleta, 92\% das amostras apresentaram crescimento, sendo 57,1\% indicativas da presença de $S$. aureus, $22,2 \%$ indicativas da presença de $S$. epidermidis e $12,7 \%$ tanto $S$. aureus quanto $S$. epidermidis.

Em relação ao celular, no BHI caldo, observou-se crescimento em 98,4\% das amostras da capa do celular, enquanto na tela, verificou-se crescimento em 95,2\%. Quanto ao Sabouraud 
caldo, 52,4\% das amostras da capa do celular apresentaram crescimento, enquanto na tela, houve crescimento em $38,1 \%$ das amostras. No BHI ágar, tanto a tela quanto a capa de todos os celulares apresentaram crescimento. Já no Sabouraud ágar todas as amostras coletadas de capa de celular apresentaram crescimento e $90,5 \%$ das amostras coletadas da tela apresentaram crescimento.

No que concerne o ágar Manitol Salgado, na capa do celular, 98,3\% das amostras apresentaram crescimento, sendo $31,7 \%$ indicativas da presença de $S$. aureus, $58,7 \%$ indicativas da presença de $S$. epidermidis e $7,9 \%$ indicativos da presença das duas espécies bacterianas. Já na tela, $98,5 \%$ das amostras apresentaram crescimento, sendo 39,7\% indicativas para $\mathrm{S}$. aureus, $54 \%$ para $S$. epidermidis e 4,8\% para as duas espécies bacterianas.

Dos 63 participantes da pesquisa, 68,3\% eram do sexo feminino e $31,7 \%$ eram do sexo masculino. A idade dos participantes variou entre 19 a 61 anos, com média de idade de 22,97. Em relação ao material da maleta, $73 \%$ apresentaram maleta de plástico, enquanto $27 \%$ apresentaram maleta de couro. Apenas $14,3 \%$ dos indivíduos afirmaram fazer uso da maleta por menos de 6 meses, todos esses indivíduos pertenciam ao quarto período do curso, enquanto $69,8 \%$ afirmaram fazer uso da maleta de 6 meses a 3 anos e 15,9\% fazem uso da maleta há mais de 3 anos.

Em relação à orientação sobre a limpeza da maleta, um aluno afirmou já ter recebido alguma orientação. Apenas 7,9\% afirmaram fazer a desinfecção da maleta. Desses, 1 afirmou fazer a limpeza duas vezes por período, 2 afirmaram fazer a limpeza 1 vez por período, 1 afirmou fazer a limpeza aproximadamente 5 vezes por período, e 1 afirmou fazer a limpeza uma vez por ano. No que diz respeito ao produto que esses usavam para fazer a limpeza, três (4,8\%) afirmaram fazer a limpeza com álcool 70\%, enquanto $2(3,1 \%)$ afirmaram fazer a limpeza com detergente e água. No que diz respeito ao tipo de celular, 98,4\% dos alunos possuíam celular com tela sensível ao toque (touchscreen), enquanto 1,6\% possuía celular de teclado.

\section{Discussão}

No presente estudo, observou-se contaminação por bactérias e fungos em todas as 63 maletas coletadas. Com os meios de cultura utilizados, foi possível revelar a presença de bactérias e fungos na alça, fundo interno e fundo externo das maletas dos estudantes de Odontologia da UFPB. 
Esses dados são corroborados por estudo que teve como objetivo investigar a presença de microrganismos em 80 maletas de estudantes de Odontologia do estado de São Paulo². Em todas as amostras coletas foi detectada a presença de microrganismos, sendo identificados cocos gram-positivos, beta hemolítico, alfa hemolítico e gama hemolítico, em sete amostras; bacilos gram-negativos, enterobactérias, em cinco amostras e coliformes, em três amostras.

Dentre os meios utilizados no nosso estudo, destaca-se o ágar Manitol Salgado, seletivo para bactérias Staphylococcus spp. O Staphylococcus aureus é comum na microbiota humana, sendo encontrado na pele e nas fossas nasais de indivíduos saudáveis ${ }^{13,14}$. Contudo, pode provocar doenças que vão desde uma simples infecção até infecções de maior gravidade. O S. aureus traz maior risco para pacientes diabéticos e HIV-positivos, que podem ser comumente atendidos na clínica odontológica, visto que pode causar diversos processos infecciosos, que variam desde infecções cutâneas crônicas, até infecções sistêmicas ${ }^{14}$.

Uma pesquisa realizada por com o objetivo de verificar a presença de Staphylococcus aureus em diferentes superfícies de uma Clínica Escola de Odontologia do Curso de Odontologia da Universidade Luterana do Brasil (ULBRA) coletou amostras do braço da cadeira do paciente, do avental utilizado pelo paciente no momento do atendimento, da luva do dentista da cuspideira e da alça do refletor ${ }^{13}$. Os resultados demonstraram contaminação de $34 \%$ para $S$. aureus, revelando que durante $\mathrm{o}$ atendimento odontológico as superfícies do consultório tornaram-se contaminadas.

Outro estudo investigou a presença de microrganismos nos aparelhos radiográficos utilizados na Clínica de Radiologia da Universidade de Taubaté ${ }^{15}$. Os resultados comprovaram um índice médio de contaminação de $50 \%$, sendo mais comumente encontrados microrganismos do gênero Staphylococcus, Candida e a espécie Streptococcus mutans.

No presente estudo, além da coleta microbiológica, o questionário respondido pelo participante da pesquisa apanhava informações do proprietário da maleta como sexo, idade, período do curso, se já foi instruído a fazer a desinfecção da maleta, se fazia a desinfecção e qual produto era utilizado.

Dos participantes, 98,4\%, correspondente a 62 indivíduos, responderam nunca ter recebido orientações sobre a limpeza da maleta. Dos indivíduos participantes, 7,9\% afirmaram fazer a limpeza da maleta com produtos como álcool $70 \%$ ou água e detergente. Podemos comprovar que essa limpeza não está sendo eficaz, tendo em vista que não foi observada diferença numérica de contaminação entre os indivíduos que afirmavam limpar a maleta e os que 
não limpavam, destacando-se a necessidade da criação de um protocolo eficaz para a limpeza das maletas.

Outro aspecto importante a ser destacado é o fato de que $27 \%$ dos participantes apresentarem a maleta de couro, que internamente é revestida por tecido. O Manual de Biossegurança de Universidade São Leopoldo Mandic proíbe o uso de maletas revestidas de tecidos nas clínicas, sendo permitidas apenas maletas de fibra ou plástico, tendo em vista que as revestidas de tecido não permitem desinfecção efetiva ${ }^{16}$.

Como as clínicas do curso de Odontologia da UFPB só começam a partir do quinto período, esperava-se que a contaminação nas maletas dos estudantes do quarto período fosse inferior, mas não foi observada diferença numérica de contaminação entre os períodos. Também não foi encontrada diferença de contaminação em relação ao tempo de uso da maleta, ou seja, maletas com menos de 6 meses de uso apresentavam tanta contaminação quanto maletas utilizadas há mais de 3 anos.

Atualmente, o telefone celular se tornou cada vez mais presente na rotina da população por facilitar a comunicação. Assim como outros objetos do nosso cotidiano, como teclados de computador, cédulas de dinheiro, entre outros, os microrganismos também estão presentes nos aparelhos celulares. Logo, estes podem ser responsáveis pela disseminação de microrganismos, gerando contaminação.

Através do presente estudo, no qual foram analisadas a capa e a tela de 63 telefones celulares de estudantes de Odontologia. Em relação à contaminação por bactérias, todos os celulares apresentaram contaminação tanto na capa quanto na tela. Quanto à contaminação por fungos, todas as amostras apresentaram contaminação na capa do celular, e 90,5\% das amostras coletadas de telas de celular apresentaram crescimento.

Quando a contaminação por microrganismos Staphylococcus spp., 98,4\% das amostras tanto da capa quanto da tela apresentaram contaminação. $\mathrm{Na}$ capa do celular, 31,7\% das amostras cultivadas são indicativas de Staphylococcus aureus, enquanto 58,7\% são indicativas de Staphylococcus epidermidis. Já na tela do celular, 98,4\% das amostras apresentaram crescimento, sendo $39,7 \%$ indicativas de Staphylococcus aureus e $54 \%$ indicativas de Staphylococcus epidermidis.

Um estudo feito com 67 celulares pertencentes a profissionais de um hospital revelou contaminação em todos os aparelhos, entretanto celulares de teclado apresentavam maior contaminação que os celulares touchscreen, o que eles acreditam ser porque o celular de teclado apresenta mais irregularidades, que permite abrigar mais bactérias ${ }^{17}$. Esse estudo revelou ainda 
que $13 \%$ dos celulares estavam contaminados com Staphylococcus aureus resistentes ao antibiótico Meticilina ou Enterococcus spp. resistentes ao antibiótico Vancomicina. No presente estudo não foi possível fazer a distinção entre celulares de teclado e tela touchscreen, tendo em vista que apenas 1 pessoa coletada possuía celular de teclado.

Corroborando o presente estudo, outras pesquisas que objetivaram avaliar a presença de microrganismos patogênicos em superfícies de celulares de pacientes e profissionais da área de saúde revelaram contaminação em todos ou em grande parte dos celulares coletados. Em estudo realizado 53\% das amostras coletas foi identificado S. aureus e em 50\% Staphylococcus negativo no teste da coagulase ${ }^{18}$. Em outro estudo $6,7 \%$ dos profissionais apresentaram Staphylococcus aureus resistentes à penicilina no celular ${ }^{19}$.

Levando-se em consideração que os celulares estão em contato direto com o rosto e com as mãos, e que os celulares podem ser utilizados constantemente, até mesmo dentro da clínica Odontológica, no intervalo entre um paciente e outro, esses podem servir como fonte de disseminação de bactérias patogênicas tanto para a equipe profissional, como também para os pacientes.

Um estudo realizado revelou que microrganismos isolados em telefones móveis são idênticos aos isolados nas mãos do dono. Nessa perspectiva, podemos concluir também que a contaminação pode ser originária de hábitos de higiene, tento em vista que se a higienização das mãos for feita de maneira correta após a manipulação do celular, haverá uma diminuição da disseminação da contaminação ${ }^{20}$.

Como limitação de estudo pode-se citar a dificuldade em realizar as coletas, visto que havia dependência da disponibilidade dos alunos em fornecer os objetos de estudo para análise.

Independente da origem ou forma de coleta e de avaliação, os dados dessa pesquisa estão em sintonia com outros estudos que mostram resultados similares. $E$ todos esses trabalhos convergem para a importância de respeitar e seguir as normas de biossegurança constantemente. Assim, no caso da odontologia, todos os estudantes devem adquirir o hábito de fazer a desinfecção das maletas e do celular com frequência e a higienização das mãos sempre que possível. Do mesmo modo, todos devem evitar o uso e a manipulação do celular no ambiente de clínica e se fizer uso desse item proceder com a higienização das mãos logo após o manuseio. 


\section{Conclusão}

A presença de microrganismos nas maletas e celulares dos estudantes de Odontologia demonstra o potencial que esses itens possuem para contaminação e disseminação de microrganismos patogênicos para a clínica odontológica.

\section{Referências}

1.Brasil. Ministério da Saúde. Classificação de Risco dos Agentes Biológicos. Brasília: Editora do Ministério da Saúde. 2006. 36p.

2.Haddad Filho MS, Leal TP, Belasalma LFF, Bacci JE, Santos MTBR, Medeiros JMF. Análise da presença de microrganismos do interior de maletas transportadas por alunos de graduação. Rev. Odontol. Univ. Cid. São Paulo. 2012;24(1):26-34.

3.Teixeira CS, Pasternak-Junior B, Silva-Sousa YTC, Correa-Silva SR. Medidas de prevenção pré e pós-exposição a acidentes perfurocortantes na prática odontológica. Rev. odonto ciênc. 2008;23(1):10-14.

4.Vasconcelos MMVB, Brasi CMV, Mota CCBO, Carvalho NR. Avaliação das normas de biossegurança nas clínicas odontológicas da UFPE. Odontologia. Clín.-Científ.2009;8(2):151-156.

5.Taiwo JO, Adrtinokun GA. Assessing cross infection prevention measures at the Dental Clinic, University College Hospital, Ibadan. African Journal of Medicine and Medical Sciences.2002; 31(3): 213-217.

6. Thomas MV, Jarboe G, Frazer RQ. Infection control in the dental office. Dent Clin North Am. 2008;52(3):609-628.

7.Cunha VJ, Rocha SC, Onofre MA, Campos AA, Sposto MR. Avaliação do controle de infecção cruzada nas clínicas de graduação do curso de odontologia. Rev. Odontol. UNESP. 1997;26(2): 307-316.

8.Pinto KML, Paula CR. Protocolo de Biossegurança no Consultório Odontológico: Custo e Tempo. Rev. biociênc. 2003;9(4):19-23.

9.Ferreira RA. Barrando o invisível. Rev. Assoc. Paul. Cir. Dent. 1995;49(6):417-427. 
10.Machado GL, Kather JM. Estudo do controle da infecção cruzada utilizada pelos cirurgiões dentistas de Taubaté. Rev.biociênc. 2002;8(1):37-44.

11.Serra MC, Garcia PPNS, Henriques C, Matsuzaki R. Medidas de proteção utilizadas por cirurgiões-dentistas para o controle da infecção cruzada no consultório odontológico. Robrac. 2000;9(28):36-39.

12.Silva PEB, Patrocínio MC, Neves ACC. Avaliação da conduta de biossegurança em clínicas odontológicas de graduação. Rev.biociênc. 2002;8(1):45-52.

13.Martins JR, Cappelari JFC, Santos RB, Weigert KL, Gelatti LC, Santos O. Presença de Staphylococcus aureus em diferentes superfícies do ambiente clínico odontológico. Revista Fasem Ciências. 2013;3(1):92-99.

14.Santos AL, Santos DO, Freitas CC, Ferreira BLA, Afonso IF, Rodrigues CR, et al. Staphylococcus aureus: visitando uma cepa de importância hospitalar. J Bras Patol Med Lab. 2007;43(6):413-423.

15.Silva FC, Antoniazi MCC, Rosa LP, Jorge AOC. Estudo da contaminação microbiológica em equipamentos radiográficos. Rev. Biociênc. 2003;9(2):35-43.

16.Silva ASF, Flório FM, Ramacciato JC, Cury PR, Motta RHL, Teixeira RG. Protocolo de Biossegurança, 2011; [acesso em 20 de dez de 2015] Disponível em:

http://www.slmandic.edu.br/download/biosseguranca.pdf

17.Pal P, Roy A, Moore G, Muzslay M, Lee E, Alder S, et al. Keypad mobile phones are associated with a significant increased risk of microbial contamination compared to touch screen phones. Journal of Infection Prevention. 2013;14(2):65-68.

18.Selim HS, Abaza AF. Microbial contamination of mobile phones in a health care setting in Alexandria, Egypt. GMS Hygiene and Infection Control. 2015;10(1):1-21.

19.Stuchi RAG, Oliveira CHAS, Soares BM, Arreguy-Sena C. Contaminação bacteriana e fúngica dos telefones celulares da equipe de saúde num hospital em Minas Gerais. Cienc Cuid Saude. 2013;12(4):760-767.

20.Khivsara A, Sushima T, Dhanasheree B. Typing of Staphylococcus aureus from mobile phones and clinical samples. Current Science. 2006;90(7):910-912. 